\title{
Influence of size disparity of transplanted hearts on cardiac growth in infants and children
}

\author{
Eva Maria Delmo Walter, MS, MD, PhD, ${ }^{a}$ Michael Huebler, MD, ${ }^{a}$ Stephan Schubert, MD, ${ }^{\mathrm{b}}$ \\ Hans Lehmkuhl, MD, PhD, ${ }^{\mathrm{c}}$ Yuguo Weng, MD, PhD, ${ }^{\mathrm{a}}$ Felix Berger, $\mathrm{MD}, \mathrm{PhD},{ }^{\mathrm{b}}$ and \\ Roland Hetzer, $\mathrm{MD}, \mathrm{PhD}^{\mathrm{a}}$
}

\begin{abstract}
Objective: We aimed to evaluate the influence of size disparity of the transplanted heart on cardiac growth in infant and child recipients by comparing donor body surface area (BSA) and cardiac dimensions during transplantation to the corresponding parameters of the recipient over a period of time.
\end{abstract}

\begin{abstract}
Methods: A retrospective review of medical and echocardiographic records of 147 children (5.3 \pm 4.0 ; median, 4.1; range, 1 month-15 years) who underwent orthotopic heart transplantation was done. The patients were divided into age groups as follows: less than 1 year $(n=23), 1$ to 2 years $(n=26)$, more than 2 to 5 years $(n=18)$, more than 5 to 10 years $(n=27)$, and more than 10 to 15 years $(n=53)$. Donor/recipient BSA ratio was determined during transplantation. Cardiac dimensions were measured 30 days after transplantation and compared at 1 year, 2 to 5 years, and 5 to 10 years after transplantation.

Results: There were no significant differences in the ventricular end-diastolic diameter, volumes, and mass among those with a donor/recipient BSA ratio of less than $0.80,0.8$ to 1.2 , and more than $1.2(P=.80, .44$, and .48 , respectively). In all the cardiac dimensions and volumes measured, donor-recipient mismatch did not influence the continuous growth of the heart, as indicated by the measured parameters, in accordance with the recipients' increase in BSA over time. All calculated Z-scores at 1 year, 2 to 5 years, and 6 to 10 years after transplantation were normal when indexed to BSA.
\end{abstract}

Conclusions: This study demonstrates that despite size disparity of a transplanted heart, it undergoes normal growth in diastolic dimensions, volumes, and myocardial mass over time as appropriate for body growth after cardiac transplantation in infants and children. (J Thorac Cardiovasc Surg 2012;143:168-77)

Great advances have been made in the field of pediatric heart transplantation since the first unsuccessful effort in a 17-day-old child with a severe form of Ebstein anomaly by Kantrowitz and associates ${ }^{1}$ in Brooklyn, New York, in December 1967, the first human heart transplant in the United States. This attempt showed the feasibility of heart transplantation in children and it is now widely accepted as a treatment modality for infants and children with end-stage cardiomyopathy or noncorrectable congenital heart diseases. ${ }^{2-4}$ Several previous investigations $^{5-9}$ in recent years have focused on the long-term function of the transplanted heart. However, there is a scarcity of information regarding the growth and

From the Departments of Cardiothoracic and Vascular Surgery, ${ }^{\mathrm{a}}$ Pediatric Cardiology and Congenital Heart Diseases, ${ }^{\mathrm{b}}$ and Cardiology, ${ }^{\mathrm{c}}$ Deutsches Herzzentrum Berlin, Berlin, Germany.

Disclosures: Authors have nothing to disclose with regard to commercial support.

Read at the 91st Annual Meeting of The American Association for Thoracic Surgery, Philadelphia, Pennsylvania, May 7-11, 2011.

Received for publication May 13, 2011; accepted for publication Sept 26, 2011; available ahead of print Oct 31, 2011.

Address for reprints: Eva Maria Delmo Walter, MS, MD, PhD, Deutsches Herzzentrum Berlin, Augustenburger Platz 1, 13353 Berlin, Germany (E-mail: delmo-walter@ dhzb.de).

0022-5223/\$36.00

Copyright (C) 2012 by The American Association for Thoracic Surgery doi:10.1016/j.jtcvs.2011.09.041 development of the transplanted heart in infants and children, as well as data addressing heart remodeling after transplantation. Previous studies ${ }^{8-11}$ demonstrated that after pediatric cardiac transplantation, cardiac chamber growth is normal over the long-term period, but few publications ${ }^{12,13}$ have focused on ventricular growth in children after cardiac transplantation, and the patterns of changes in cardiac dimensions after transplantation have remained unclear. ${ }^{12}$ This issue is especially important inasmuch as the elucidation of changes in ventricular dimensions and volumes during this period would improve our understanding of the process of adaptation of the donor heart to the recipient's circulation, especially after donor-recipient size disparity transplantation. Several studies ${ }^{14-17}$ have focused on the impact of donor/recipient weight ratio on survival and late outcome after pediatric heart transplantation. Presently, there is no known long-term study available regarding the impact of size disparity of the transplanted heart on cardiac growth in infants and children over time.

We therefore aimed to evaluate the influence of donor-recipient size disparity on the growth of the transplanted heart in infants and children by comparing donor body surface area (BSA) and cardiac dimensions during transplantation with the corresponding parameters of the recipient over a period of time. 


\section{Abbreviations and Acronyms \\ BSA = body surface area \\ $\mathrm{LV} \quad=$ left ventricular \\ $\mathrm{RV} \quad=$ right ventricular}

\section{PATIENTS AND METHODS}

The Institutional Review Board of Deutsches Herzzentrum Berlin approved this retrospective study and waived the need for patient consent.

\section{Patients}

We studied 147 patients who underwent orthotopic heart transplantation at the Deutsches Herzzentrum Berlin between 1986 and 2010. Indications for heart transplantation were cardiomyopathy, myocarditis, or endocardial fibrosis in 115 patients and congenital heart disease in 32 patients. Medical records were reviewed for age, gender, weight, height, BSA, and indications for transplantation. The donor's age, height, and weight at the time of transplantation were likewise noted. Patients were reviewed on the basis of age groups $(<1,1-2,>2-5,>5-10$, and $>10-15$ years old $)$ and on their donor/recipient BSA ratio (ie, $<0.8,0.8-1.2$, and $>1.2$ ).

\section{Immunosuppression Protocol}

Our triple-drug immunosuppressive therapy consists of an induction therapy designed to reduce the incidence of early rejection and is given 6 hours after heart transplantation with intravenous antithymocyte globulin $1.5 \mathrm{mg} / \mathrm{kg}$ on the first 3 days accompanying intravenous prednisolone at 2.5 to $5 \mathrm{mg} \cdot \mathrm{kg}^{-1} \cdot \mathrm{d}^{-1}$. Thereafter, steroids are tapered at $2 \mathrm{mg} \cdot \mathrm{kg}^{-1}$. $\mathrm{d}^{-1}$ orally. Cyclosporine is started preoperatively at $6 \mathrm{mg} / \mathrm{kg}$ orally and is continued at $2 \mathrm{mg} / \mathrm{kg}$ intravenously or $6 \mathrm{mg} / \mathrm{kg}$ orally to target a trough level of $250 \mathrm{ng} / \mathrm{mL}$. Mycophenolate mofetil is started preoperatively at $1000 \mathrm{mg}$ orally and is continued at $1000 \mathrm{mg}$ twice daily either orally or intravenously. This triple therapy with cyclosporine/mycophenolate mofetil/ steroids is alternatively applied with everolimus $(2 \times 0.75 \mathrm{mg}$ orally daily, target trough levels $3-8 \mathrm{ng} / \mathrm{mL}$ ) instead of mycophenolate mofetil if there are no contraindications to everolimus. ${ }^{18}$

\section{Follow-up}

No patients were lost to follow-up. Follow-up data with series of echocardiograms of the children who underwent transplantation between 1986 and 2010 were provided by the Department of Congenital Heart Disease/ Pediatric Cardiology and Department of Clinical Studies, Deutsches Herzzentrum Berlin, and by written correspondence from the referring physicians. It is our institutional policy that each transplant patient undergo echocardiographic examination on a weekly basis from the first posttransplant week until 24 weeks after transplant. Thereafter, an echocardiographic follow-up protocol consisting of selected posttransplant time intervals is followed. The mean duration of follow-up was $13 \pm$ 0.8 years (range, 5 months -24 years), providing a total of 1157.79 patient-years.

\section{Echocardiographic Evaluation of Cardiac Dimensions, Mass, and Volume}

Echocardiogram reports were analyzed in detail to determine the changes in cardiac dimensions, mass, and volume over the follow-up period. Echocardiographic evaluations were done 30 days, 1 year, 5 years, 10 years, and 15 years after transplantation. Each echocardiogram included an evaluation of cardiac anatomy, ventricular function, and dimensions by 2 -dimensional imaging with pulsed and color Doppler mapping.

\section{Measurements}

Ventricles were imaged from the parasternal and subxiphoid long and short axes, as well as the apical 4-chamber view. End-diastolic diameter was measured in the anteroposterior plane as the maximal diastolic diameter between the septal to posterior wall at the level of the papillary muscle tips. Posterior wall thickness was measured in diastole between the papillary muscles at the level of the papillary muscle tips. Ventricular length was measured in diastole from the midpoint of the mitral valve annulus to the apical endocardium. Ventricular volume was calculated using the biplane area-length method ${ }^{19,20}$ (Volume $=5 / 6 \mathrm{~L} \times \mathrm{A}$ ), where $\mathrm{L}$ is the left ventricular (LV) length measured from the midpoint of the mitral valve annulus to the apical endocardium and A is the planimetered LV shortaxis cross-sectional area. Volume was measured in systole (minimal dimension) and diastole (maximal dimension). The formula used for calculation of LV end-diastolic volume (LVEDV) is: LVEDV $=$ LVIDd. $^{3}$ Ventricular mass was calculated as 1.04 ([IVSd - LVIDd - LVPWTd]), ${ }^{3}$ where IVSd is interventricular septal thickness in diastole, LVIDd is LV end-diastolic minor axis dimension, and PWT is LV posterior wall thickness in diastole.

To adjust for age, body size, and growth-related changes in ventricular dimensions, linear measurements were indexed to the square root of $\mathrm{BSA}^{0.5}$, while volumetric and mass measurements were indexed to $\mathrm{BSA}^{1.5}{ }^{21}$

\section{Statistical Analysis}

Data were analyzed with SPSS 16.0 (SPSS, Inc, Chicago, Ill) for Windows software program. Demographic and echocardiographic variables are expressed as mean \pm standard deviation and mean \pm standard error of the mean, respectively, as well as range, as appropriate. Univariate comparisons of mean ventricular diameter, volume, and mass and mean changes indexed to the donor's BSA with those indexed to the recipient's BSA at selected posttransplant time intervals (30 days, 1 year, 2-5 years, and 6-10 years) were compared using the Student $t$ test. Correlations and linear regression analyses with the least squares method were used to evaluate the relation between donor/recipient BSA ratios and the measured cardiac parameters. To facilitate comparison between cardiac dimensions, we computed Z-values as follows: Z-score 0 (measured value-mean value of normal controls)/standard deviation of normal controls. Comparison of survivals was performed by the log-rank test. Cumulative survival was analyzed according to Kaplan-Meier estimates with $95 \%$ confidence intervals.

\section{Definition of Normal Growth}

Normal growth was defined as a lack of Z-score change between followup periods. Failure of growth of any dimension would be detected as a statistically significant decline in Z-score. To verify that our method of stratifying data from the normal patient population did not itself introduce errors, we reanalyzed the raw data from one measurement, the ventricular end-diastolic diameter, using a second statistical method to determine Z-score divisions. No effect on our analysis of Z-score changes was found.

\section{RESULTS \\ Patient Profile}

The demographic profile of infants and children who underwent cardiac transplantation is shown in Table 1. Mean age at transplantation was $5.3 \pm 4.0$ years (median, 4.1 years; range, 1 month-15 years). Mean donor age was $14.9 \pm 8.1$ years (range, 1 month-60 years). Mean donor/recipient BSA ratio is 1.6. Age at follow-up is a mean of $15.6 \pm 8.49$ years (range, 2.9 months -33.9 years).

\section{Linear Growth}

Over time, linear growth was normal in these patients. Five patients were 3 standard deviations below normal at 
TABLE 1. Demographic profile of heart transplant children

\begin{tabular}{|c|c|c|}
\hline Demography & Recipient & Donor \\
\hline No. of patients $(\mathrm{M} / \mathrm{F})$ & $147(82 / 63)$ & $147(89 / 58)$ \\
\hline Age at heart transplantation (mean $\pm \mathrm{SD}, \mathrm{y})$ & $5.3 \pm 4.0$ y (range, $1 \mathrm{mo}-15 \mathrm{y})$ & $14.93 \pm 8.11$ y (range, $1 \mathrm{mo}-60 \mathrm{y})$ \\
\hline Age at follow-up (mean $\pm \mathrm{SD}, \mathrm{y})$ & $15.6 \pm 8.49$ y (range, 2.9 mo-33.9 y) & \\
\hline Mean weight at transplantation (mean $\pm \mathrm{SD}, \mathrm{kg}$ ) & $28.1 \pm 19.4$ (median, 23.5; range, 3.5-67) & $48.73 \pm 22.9$ (median, 32; range, $4-90$ ) \\
\hline Mean height at transplantation (mean $\pm \mathrm{SD}, \mathrm{cm}$ ) & $123.5 \pm 33.5$ (median, $132 ;$ range, $50-177)$ & $141.09 \pm 38.2$ (median, 38; range, 74-190) \\
\hline Mean BSA at transplantation (mean $\left.\pm \mathrm{SD}, \mathrm{m}^{2}\right)$ & $1.03 \pm 0.49($ median, $1.02 ;$ range, $0.2-1.5)$ & $1.64 \pm 0.52$ (median, $1.45 ;$ range, $0.2-2.2$ ) \\
\hline
\end{tabular}

$S D$, Standard deviation; $B S A$, body surface area.

early follow-up but were close to the normal range at late follow-up. These included 3 infants who showed delayed linear growth while still receiving steroids and 2 children on high-dose immunosuppressants because of repeated rejection episodes. In these patients with poor linear growth, cardiac chamber growth occurred and was appropriate for BSA. Over time, the mean change in BSA was $0.28 \pm$ $0.03 \mathrm{~m}^{2}$ (range, $0.12-0.50 \mathrm{~m}^{2}$ ). By expressing cardiac growth as a function of BSA, we were able to compensate for those transplant patients who showed delayed linear growth.

\section{Echocardiographic Data: Cardiac Dimensions}

Changes in ventricular diameter, volume, and mass after transplantation for all patients are detailed in Tables 2 and 3. Thirty days after transplantation. All patients had initially higher right ventricular (RV) (mean, $18.3 \pm 1.2 \mathrm{~cm} /$ $\mathrm{m}^{2} \mathrm{BSA}$ ) and LV (mean, $28.1 \pm 2.4 \mathrm{~cm} / \mathrm{m}^{2} \mathrm{BSA}$ ) enddiastolic diameters, $\mathrm{RV}$ (mean, $124.5 \pm 2.31 \mathrm{~mL} / \mathrm{m}^{2}$ BSA) and LV (mean $110.67 \pm 2.7 \mathrm{~m}^{2} \mathrm{BSA}$ ) end-diastolic volumes, and RV (mean, $21.9 \pm 2.2 \mathrm{~g} / \mathrm{m}^{2} \mathrm{BSA}$ ) and $\mathrm{LV}$ (mean, $53.8 \pm 4.3 \mathrm{~g} / \mathrm{m}^{2} \mathrm{BSA}$ ) mass in the first 30 days after heart transplantation when compared with their BSA (Table 2).

One year after transplantation. Comparing the values obtained during the first 30 days of transplantation, there was a significant decrease $(P=.00)$ in RV (mean, $14.8 \pm$ $1.0 \mathrm{~cm} / \mathrm{m}^{2} \mathrm{BSA}$ ) and LV (mean, $23.8 \pm 1.9 \mathrm{~cm} / \mathrm{m}^{2}$ BSA) end-diastolic diameters, $\mathrm{RV}$ (mean, $101.7 \pm 2.6 \mathrm{~mL} / \mathrm{m}^{2}$ BSA) and LV (mean, $92.1 \pm 7.4 \mathrm{~mL} / \mathrm{m}^{2} \mathrm{BSA}$ ) enddiastolic volumes, and RV (mean, $19.9 \pm 1.5 \mathrm{~g} / \mathrm{m}^{2} \mathrm{BSA}$ ) and LV (mean, $43.8 \pm 7.4 \mathrm{~g} / \mathrm{m}^{2} \mathrm{BSA}$ ) mass during the first year after heart transplantation, regardless of the BSA ratio (Tables 2 and 3). Calculated Z-scores were normal when indexed to BSA (Table 2).

Two to 5 years after transplantation. Over the follow-up intervals of 2 to 5 years after transplantation, the ventricular end-diastolic diameters (RV mean, $21.4 \pm 1.6 \mathrm{~cm} / \mathrm{m}^{2} \mathrm{BSA}$, and LV mean, $26.5 \pm 3.4 \mathrm{~cm} / \mathrm{m}^{2} \mathrm{BSA}$ ), the ventricular enddiastolic volumes (RV mean, $109.2 \pm 2.7 \mathrm{~mL} / \mathrm{m}^{2} \mathrm{BSA}$, and $\mathrm{LV}$ mean, $\left.101.3 \pm 3.9 \mathrm{~mL} / \mathrm{m}^{2} \mathrm{BSA}\right)$, and ventricular mass (RV mean, $27.4 \pm 3.9 \mathrm{~g} / \mathrm{m}^{2} \mathrm{BSA}$, and LV mean, $67.4 \pm$ $3.8 \mathrm{~g} / \mathrm{m}^{2}$ BSA) increased in accordance with the linear growth of recipients, regardless of BSA ratio. Comparing these to the values obtained during the first posttransplantation year, these were significant increases $(P=.00)$ as well as when compared with the values obtained 30 days after transplantation (Tables 2 and 3).

Six to 10 years after transplantation. The ventricular end-diastolic diameters (RV mean, $27.17 \pm 1.1 \mathrm{~cm} / \mathrm{m}^{2}$ $\mathrm{BSA}$, and LV mean, $30.9 \pm 1.9 \mathrm{~cm} / \mathrm{m}^{2} \mathrm{BSA}$ ), the ventricular end-diastolic volumes (RV mean, $116.54 \pm 5.6 \mathrm{~mL} / \mathrm{m}^{2}$ $\mathrm{BSA}$, and LV mean, $108.54 \pm 8.0 \mathrm{~mL} / \mathrm{m}^{2} \mathrm{BSA}$ ) and ventricular mass (RV mean, $36.5 \pm 2.6 \mathrm{BSA}$, and LV mean, $79.8 \pm$ $3.2 \mathrm{~g} / \mathrm{m}^{2} \mathrm{BSA}$ ) increased proportionally 6 to 10 years after heart transplantation in all patients regardless of the BSA ratio. All echocardiographic parameters attained statistically significant difference when compared with values measured at 1 year $(P=.00)$ and 2 to 5 years $(P=.00)$ after transplantation (Tables 2 and 3 ) but were not influenced by BSA ratio.

TABLE 2. Echocardiographic data on ventricular diameter, volume, and mass during different follow-up periods

\begin{tabular}{|c|c|c|c|c|c|c|c|c|}
\hline \multirow[b]{2}{*}{ Echocardiographic variables } & \multicolumn{8}{|c|}{ Follow-up, posttransplantation time } \\
\hline & $30 \mathrm{~d}$ & $Z$-score & $1 \mathbf{y}$ & Z-score & $2-5 y$ & $Z$-score & $6-10 y$ & $Z$-score \\
\hline $\operatorname{RVEDD}\left(\mathrm{cm} / \mathrm{m}^{2}, \mathrm{BSA}\right)$, mean \pm SEM & $18.3 \pm 1.2$ & -1.9 to +3.7 & $14.8 \pm 1.0$ & -1.0 to +1.5 & $21.4 \pm 1.6$ & -1.8 to +1.6 & $27.1 \pm 1.1$ & -1.9 to +1.8 \\
\hline $\operatorname{RVEDV~}\left(\mathrm{mL} / \mathrm{m}^{2} \mathrm{BSA}\right)$, mean \pm SEM & $124.5 \pm 2.31$ & -2.0 to +3.9 & $101.7 \pm 2.6$ & -1.3 to +1.8 & $109.2 \pm 2.7$ & -1.3 to +1.9 & $116.5 \pm 5.6$ & -1.2 to +2.3 \\
\hline $\begin{array}{l}\mathrm{RV} \text { myocardial mass }\left(\mathrm{g} / \mathrm{m}^{2} \mathrm{BSA}\right) \\
\text { mean } \pm \mathrm{SEM}\end{array}$ & $21.9 \pm 2.2$ & -2.1 to +4.0 & $19.9 \pm 1.5$ & -1.4 to +1.7 & $27.4 \pm 3.9$ & -1.8 to +1.8 & $36.5 \pm 2.6$ & -1.9 to +2.4 \\
\hline $\operatorname{LVEDD}\left(\mathrm{cm} / \mathrm{m}^{2} \mathrm{BSA}\right)$, mean \pm SEM & $28.1 \pm 2.4$ & -1.9 to +3.7 & $23.8 \pm 1.9$ & -1.0 to +1.9 & $26.5 \pm 3.4$ & -1.0 to +1.9 & $30.9 \pm 1.9$ & 0.9 to 2.0 \\
\hline $\operatorname{LVEDV}\left(\mathrm{mL} / \mathrm{m}^{2} \mathrm{BSA}\right)$, mean \pm SEM & $110.6 \pm 2.7$ & -2.0 to +2.9 & $92.1 \pm 7.4$ & 1.3 to +1.8 & $101.3 \pm 3.9$ & -1.3 to +1.9 & $108.5 \pm 8.0$ & -1.2 to +2.4 \\
\hline $\begin{array}{l}\mathrm{LV} \text { myocardial mass }\left(\mathrm{g} / \mathrm{m}^{2} \mathrm{BSA}\right) \\
\text { mean, } \pm \mathrm{SEM}\end{array}$ & $53.8 \pm 4.3$ & -2.1 to +4.2 & $43.8 \pm 7.4$ & -1.4 to +1.8 & $67.4 \pm 3.8$ & -1.7 to +2.1 & $79.8 \pm 3.2$ & -1.8 to +2.3 \\
\hline
\end{tabular}

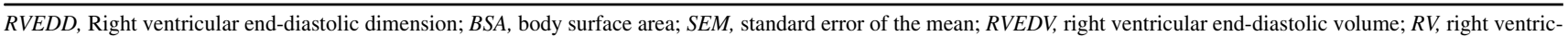
ular; $L V E D D$, left ventricular end-diastolic dimension; $L V E D V$, left ventricular end-diastolic volume; $L V$, left ventricular. 
TABLE 3. Multivariate analysis of ventricular diameter, volume, and mass during different follow-up periods

\begin{tabular}{|c|c|c|c|}
\hline & \multicolumn{2}{|c|}{ Paired sample tests } & \multirow[b]{2}{*}{$P$ value } \\
\hline & OR & $95 \% \mathrm{CI}$ & \\
\hline \multicolumn{4}{|c|}{ RVEDD $\left(\mathrm{cm} / \mathrm{m}^{2} \mathrm{BSA}\right)$} \\
\hline 1 vs 2 & 8.352 & 6.576 to 10.648 & .00 \\
\hline 1 vs 3 & 3.258 & 0.602 to 2.473 & .00 \\
\hline 1 vs 4 & 0.560 & -0.46 to 1.331 & .57 \\
\hline \multicolumn{4}{|c|}{$\operatorname{RVEDV}\left(\mathrm{mL} / \mathrm{m}^{2} \mathrm{BSA}\right)$} \\
\hline 1 vs 2 & 6.335 & 21.796 to 41.537 & .00 \\
\hline 1 vs 3 & 4.638 & 14.979 to 37.222 & .00 \\
\hline 1 vs 4 & 2.984 & 7.871 to 39.063 & .00 \\
\hline \multicolumn{4}{|c|}{ RV myocardial mass ( $\left.\mathrm{g} / \mathrm{m}^{2} \mathrm{BSA}\right)$} \\
\hline 1 vs 2 & 6.565 & 2.441 to 4.490 & .00 \\
\hline 1 vs 3 & -6.389 & -5.595 to -2.295 & .00 \\
\hline 1 vs 4 & -14.547 & -13.53 to -10.29 & .00 \\
\hline \multicolumn{4}{|c|}{$\operatorname{LVEDD}\left(\mathrm{cm} / \mathrm{m}^{2} \mathrm{BSA}\right)$} \\
\hline 1 vs 2 & 8.957 & 10.912 to 17.083 & .00 \\
\hline 1 vs 3 & 8.581 & 11.275 to 18.02 & .00 \\
\hline 1 vs 4 & 8.156 & 12.195 to 20.008 & .00 \\
\hline \multicolumn{4}{|c|}{ LVEDV $\left(\mathrm{mL} / \mathrm{m}^{2} \mathrm{BSA}\right)$} \\
\hline 1 vs 2 & 5.839 & 19.073 to 38.564 & .00 \\
\hline 1 vs 3 & 4.094 & 11.93 to 34.19 & .00 \\
\hline 1 vs 4 & 2.594 & 4.541 to 34.073 & .11 \\
\hline \multicolumn{4}{|c|}{ LV myocardial mass ( $\mathrm{g} / \mathrm{m}^{2} \mathrm{BSA}$ ) } \\
\hline 1 vs 2 & 7.311 & 10.369 to 18.059 & .00 \\
\hline 1 vs 3 & 3.429 & 2.880 to 10.736 & .00 \\
\hline 1 vs 4 & -2.71 & -4.713 to 3.577 & .78 \\
\hline
\end{tabular}

Postoperative follow-up: $1=30$ days; $2=1$ year; $3=2-5$ years; $4=6-10$ years. $O R$, Odds ratio; $C I$, confidence intervals; $R V E D D$, right ventricular end-diastolic dimension; $B S A$, body surface area; $R V E D V$, right ventricular end-diastolic volume; $R V$, right ventricular; $L V E D D$, left ventricular end-diastolic dimension; $L V E D V$, left ventricular end-diastolic volume; $L V$, left ventricular.

All calculated Z-scores during 2 to 5 years and 6 to 10 years after transplantation were normal when indexed to BSA (Table 2). Ventricular end-systolic and end-diastolic diameters fell between the 5th and 95th percentiles, and all patients demonstrated normal chamber growth. Although cardiac mass is linearly related to BSA, cardiac dimensions increase as an exponential function of BSA.

The cardiac dimensions and volumes measured are demonstrated in Figure 1, A-F. As BSA increases, there is an associated increase in cardiac dimensions and volume. The mean ventricular diameters and myocardial mass, which was $85.6 \% \pm 16.8 \%$ of that predicted normal for BSA after the first year and $96.4 \% \pm 7.5 \%$ of that predicted normal after 5 years, suggests growth and adaptation of cardiac dimensions and volumes appropriate for body growth.

\section{Donor-Recipient Sizes}

Because a size mismatch between the donor and recipient could result in early alterations in the perceived cardiac growth rate, we compared donor and recipient size by a paired Student $t$ test and found no significant differences among those with a donor/recipient BSA ratio of less than $0.8,0.8$ to 1.2 , and more than $1.2(P=.80, .44$, and .48 , respectively). Figure $2, A, B$, and $C$, shows the cardiac dimensions stratified on the basis of donor/recipient BSA ratio over the follow-up period, which were proportionate to the increase in body growth over the matched follow-up period. All recipients experienced normal volume growth commensurate with BSA growth to maintain a ratio of ventricular volume predicted for BSA of greater than $90 \%$. The ventricular mass increased in accordance with the increase in end-diastolic volume.

In all the cardiac dimensions and volumes measured, donor-recipient mismatch did not influence the continuous growth in the measured parameters according to the recipients' BSA over time.

\section{Follow-up and Survival}

The mean duration of follow-up was $13 \pm 0.8$ years (range, 5 months-24 years), providing a total of 1157.79 patient-years. Cumulative survival at 10 and 15 years is $61.7 \%$ and $42.8 \% \pm 8 \%$ (Figure $3, A$ ). When the survival is stratified on the basis of donor/recipient BSA ratio, survival is $91.2 \% \pm 6.3 .7 \%, 82.2 \% \pm 5.1 \%, 77.4 \% \pm$ $5.8 \%$, and $63.0 \% \pm 7.5 \%$ at 30 days, 1,5 , and 10 years, respectively, for a donor/recipient BSA ratio of less than 1.0; in patients with a donor/recipient BSA ratio of 1.0, survival is $81.3 \% \pm 9.8 \%$ and $67.7 \% \pm 11.9 \%$ at both 30 days and 1 year and at both 5 and 10 years, respectively; in patients with a donor/recipient weight ratio of more than 1.0 , survival is $90.4 .0 \% \pm 3.0 \%, 86.9 \% \pm 3.6 \%, 78.8 \% \pm$ $4.3 \%, 58.0 \% \pm 6.4 \%$, and $46.3 \% \pm 7.4 \%$ at 30 days and $1,5,10$, and 20 years, respectively (Figure 3, B).

There is no statistically significant difference in survivals among patients with different donor/recipient BSA ratios $(P=.53)$.

\section{DISCUSSION}

The questions of whether a transplanted heart in a newborn will grow to adult size along with the child, in the presence of size disparity, and whether the dimensional growth of the organ allows adequate function over time have been largely answered in this investigation. The other question that awaits an answer is what could be the mechanisms involved in the adaptation of a transplanted heart to its new environment, especially when an adult heart is transplanted into a child, where the size mismatch is obvious, and we are focusing on this issue in on-going investigations.

We have shown in this study that cardiac dimensions and volumes increased in size appropriate to age and BSA of the recipient over time, regardless of donor-recipient size mismatch. Over time, even a large transplanted heart adapts to its new environment accordingly and grows along with the somatic growth of the recipient. 

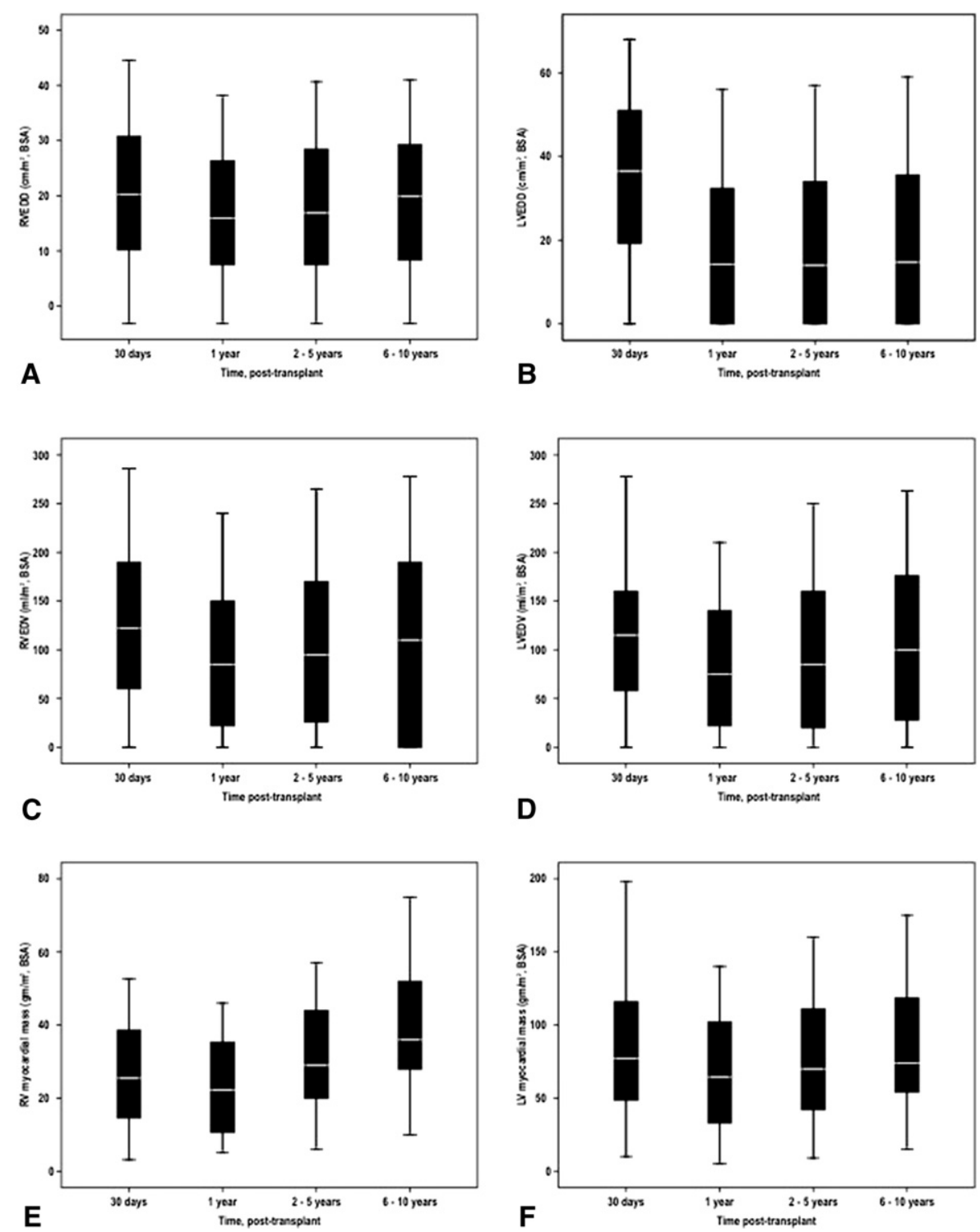

FIGURE 1. A, Right ventricular end-diastolic diameter (RVEDD). B, Left ventricular end-diastolic diameter (LVEDD). C, Right ventricular end-diastolic volume $(R V E D V)$. D, Left ventricular end-diastolic diameter $(L V E D V)$. E, Right ventricular $(R V)$ myocardial mass. F, Left ventricular $(L V)$ myocardial mass, over time. $B S A$, Body surface area.

Our results elucidate adaptation of the transplanted heart to the functional demands of the recipient circulation in the first months after transplantation in infants and children. A large donor heart would be expected to exhibit regression of ventricular mass with time as an adaptive phenomenon. ${ }^{13}$ This phenomenon may represent the effect of intrinsic time-dependent factors that regulate cardiac growth. $^{22}$ These factors are unrelated to functional demands of the heart and may involve genetic programming as well as humoral growth factors, which may persist in the recipient circulation for a period after transplantation regardless of the size of the transplanted organ. This could lead to continued growth of the myocardium in the early posttransplant period, manifesting as the early increase in ventricular mass and volume that we observed regardless of donor/recipient BSA ratio. Over time after transplantation, the effect of these intrinsic factors may be overridden by the effect of load-dependent adaptation of the heart.

It may be disputed whether our findings represent cardiac growth of a small heart to increasing cardiac output requirements and/or physiologic adaptation of a large transplanted heart. This issue is interesting and provocative. Our findings may suggest that the younger the patient is at the time of transplantation, the greater is the magnitude of early increase and subsequent decrease in 

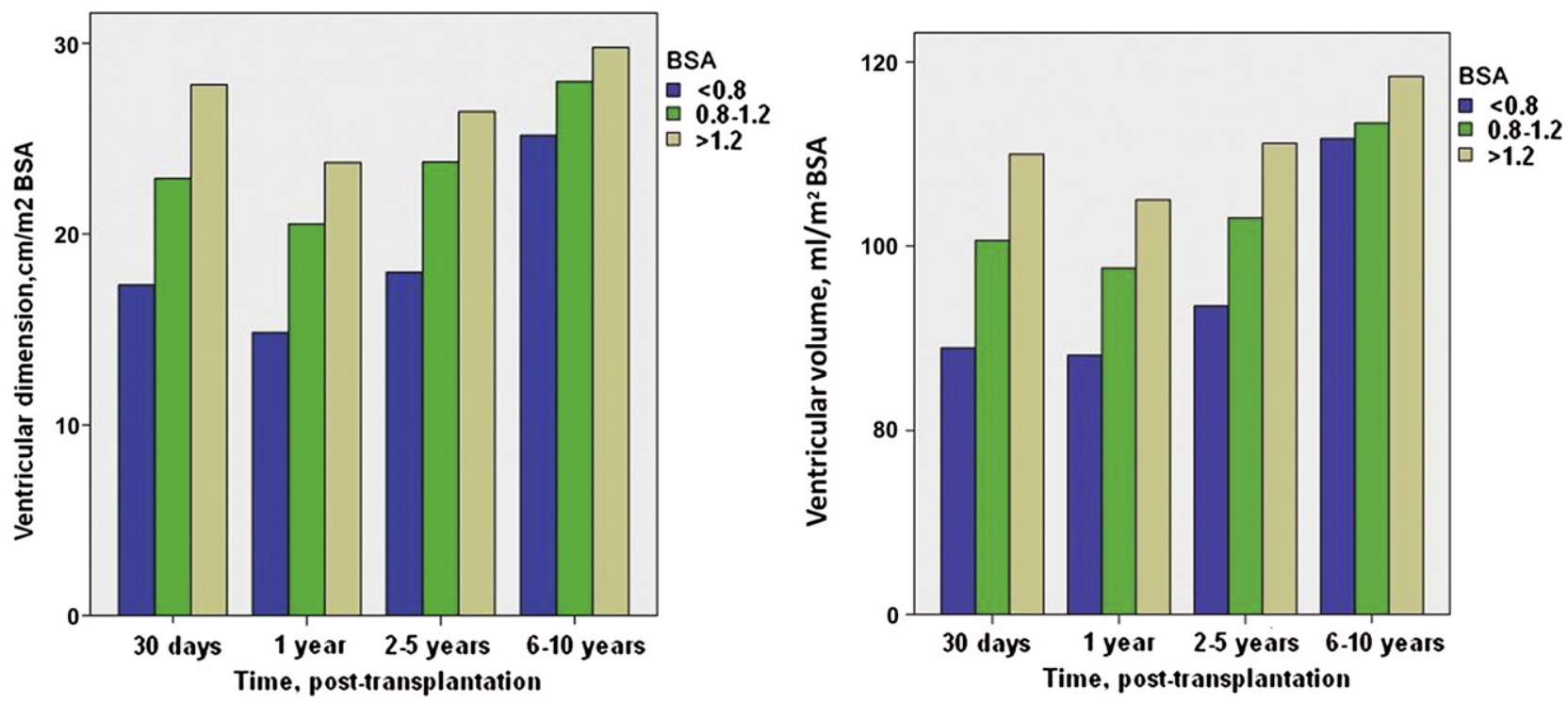

A

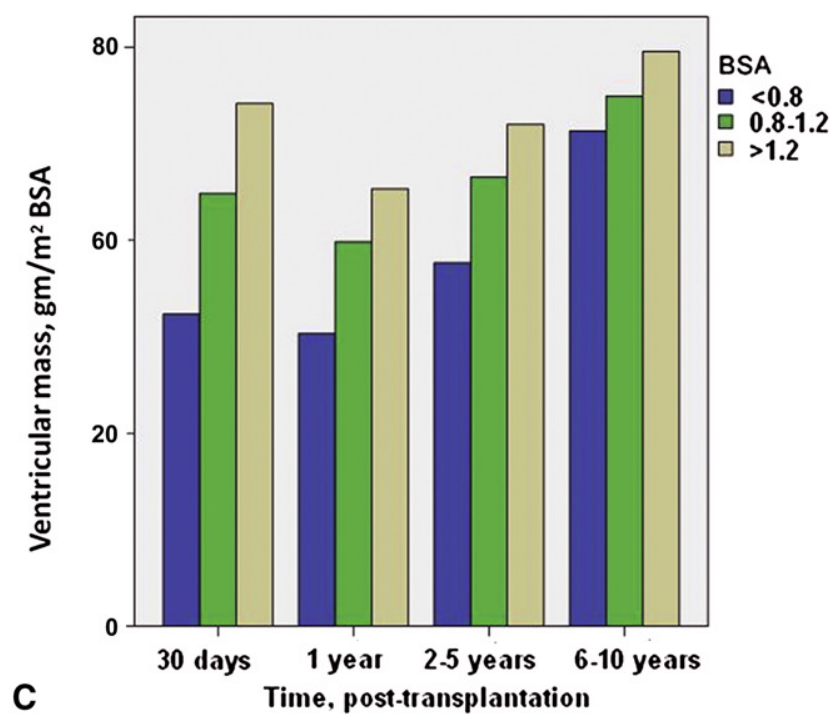

FIGURE 2. Comparison of ventricular end-diastolic diameter (A), ventricular volume (B), and ventricular mass (C), stratified according to body surface area $(B S A)$ ratio, over time.

ventricular mass with the remodeling process. Significant decrease in cardiac dimensions, volumes, and mass during the first posttransplant year clearly showed that the ventricles remodeled, which is in agreement with the findings of Hirsch and associates. ${ }^{13}$ This remodeling consisted primarily of regression of end-diastolic diameters and volumes and myocardial mass. The trigger initiating regression is likely to include the load modulation of ventricular mass. ${ }^{23}$ By 1 year after transplantation, the LV mass has decreased significantly from the original mass 30 days after transplantation, suggesting that the heart undergoes extensive adaptive changes mediated by pressure and volume factors. It is likely that neurohumoral factors and intrinsic myocyte responses to the altered pressure and volume load contribute to these altered hemodynamic adaptations.

The determinants of myocardial growth have not been defined. $\mathrm{Zak}^{22}$ demonstrated that differentiation and growth of the heart are governed by intrinsic or time-dependent factors, which include myogenesis and cardiac looping occurring in the absence of hemodynamic influences and by extrinsic factors related to the cardiac performance responding to functional demands, such as compensatory hypertrophy that follows an increase in hemodynamic load. As the body weight doubles by 6 months and triples by 1 year of age, the cardiac weight increases similarly. ${ }^{24}$ The fetal period of myocardial growth is characterized by mitotic division, and cellular proliferation continues in the early 

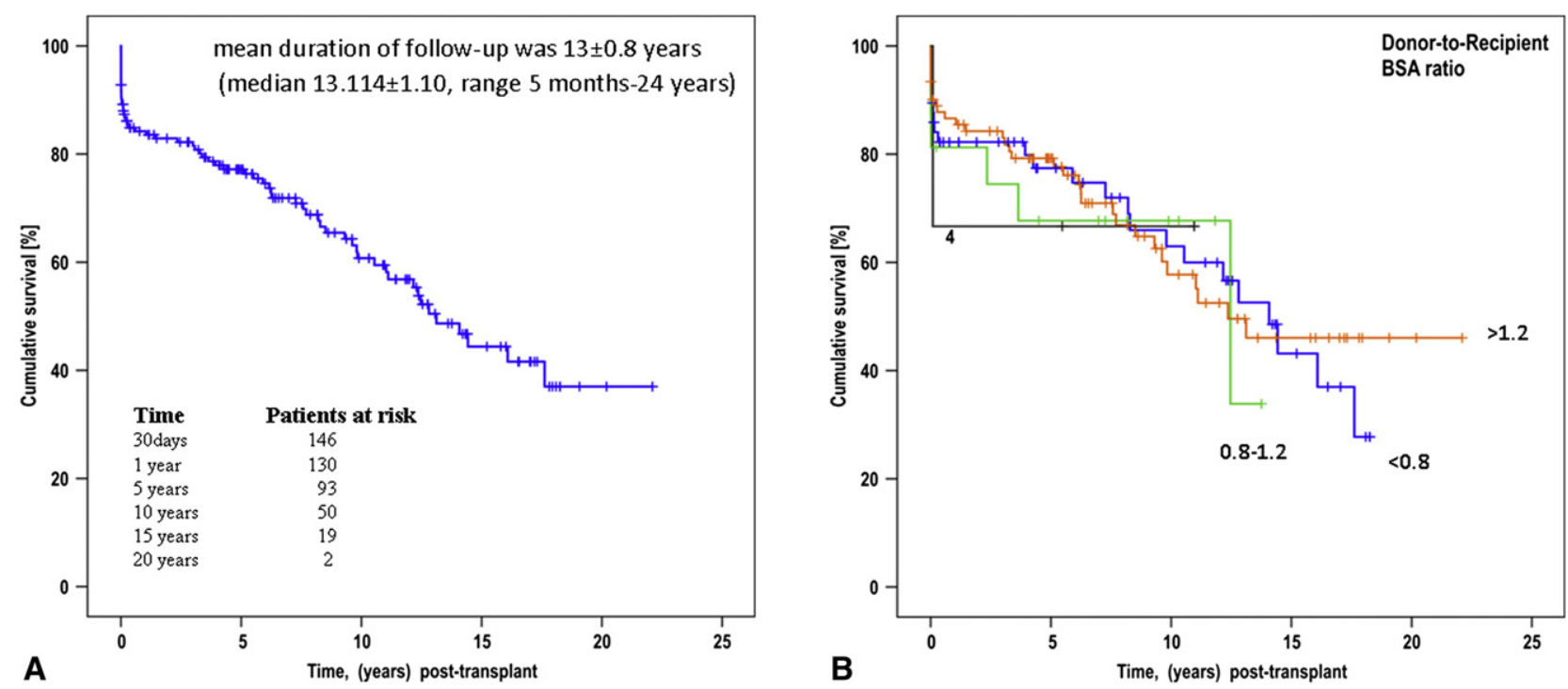

FIGURE 3. A, Cumulative survival after orthotopic heart transplantation. B, Survival stratified according to donor/recipient BSA ratio.

postnatal period with a rapid decline. Further growth is characterized by an increase in cell diameters. The signal to cease proliferation is unknown. The potential for proliferation to be restimulated remains an intriguing concept supported by the work of Chien and associates,${ }^{25}$ in which the activation of cardiac target genes resulted in embryonic gene expression.

In this study we have demonstrated that, even in the presence of delayed linear growth, normal cardiac growth occurs. Because ventricular systolic and end-diastolic dimensions may be more dependent on volume loading conditions than on increase in cell size, our long-term results are confirmative. The restrictive physiologic function observed at 1 month after transplantation normalized over a period of 1 year, adapting to the recipient circulation. This suggests that hearts can adapt rapidly to altered pressure and volume loads and show marked remodeling over time to maintain the circulatory burden.

This evidence shows that the transplanted heart has the ability to adapt to new hemodynamic burdens, suggesting that, regardless of the donor/recipient BSA ratio, the transplanted hearts could rapidly adapt to the new hemodynamic environment and that after the immediate posttransplant period the transplanted heart could maintain an appropriate circulation according to the recipient's circulatory demands.

From a clinical standpoint, the results of this study indicate that the use of oversized or undersized donor hearts within a certain range appears to be well tolerated after heart transplantation. Our policy in pediatric heart transplantation is that the donor can be 4 times larger than the recipient but should not be much smaller so as to sustain the immediate posttransplant hemodynamics. Tang and colleagues ${ }^{14}$ reported that the use of smaller allografts does not affect recipients' short- and long-term survival, and smaller allografts could therefore be accepted in pediatric heart transplantation. Patel and associates ${ }^{15}$ reported that weight ratio did not predict mortality after heart transplantation after controlling for known risk factors, propensity score adjustment, and matching. Fullerton and coworkers ${ }^{16}$ also reported that large size mismatches appear to be well tolerated in pediatric heart transplantation.

These observations do not support the contention that donor/recipient size ratio plays a dominant role in cardiac growth. However, another challenging issue may be considered: does growth occur in those transplanted adult hearts? These are evidently mismatched hearts when implanted into children. What could be the mechanism of shrinkage in size within months to 1 year after their implantation? These hearts, which have been denervated and subjected to a barrage of immunosuppressants, have already gone beyond their potential for cellular hyperplasia. We have chest $x$-ray films of these patients showing a large (adult) heart occupying such a small chest cavity (Figure 4, A), but over time, they have reduced in size, and eventually conform (Figure $4, B$ ) to the BSA of the recipient. It is indeed a provocative issue, and we are concerned to look for possible explanations as to what cellular mechanisms could be responsible. Presently, on the basis of our data at hand and the existing, albeit scant, literature, we may only postulate that there must be some existing molecular signal pathways directing this interesting response. It remains unresolved what mechanisms govern the proportional cardiac shrinkage of an adult heart transplanted into a small chest cavity that then eventually enlarges its dimensions over time in relation to the bodily growth of its recipient. This is probably a result of time-dependent genetic factors or extrinsic 


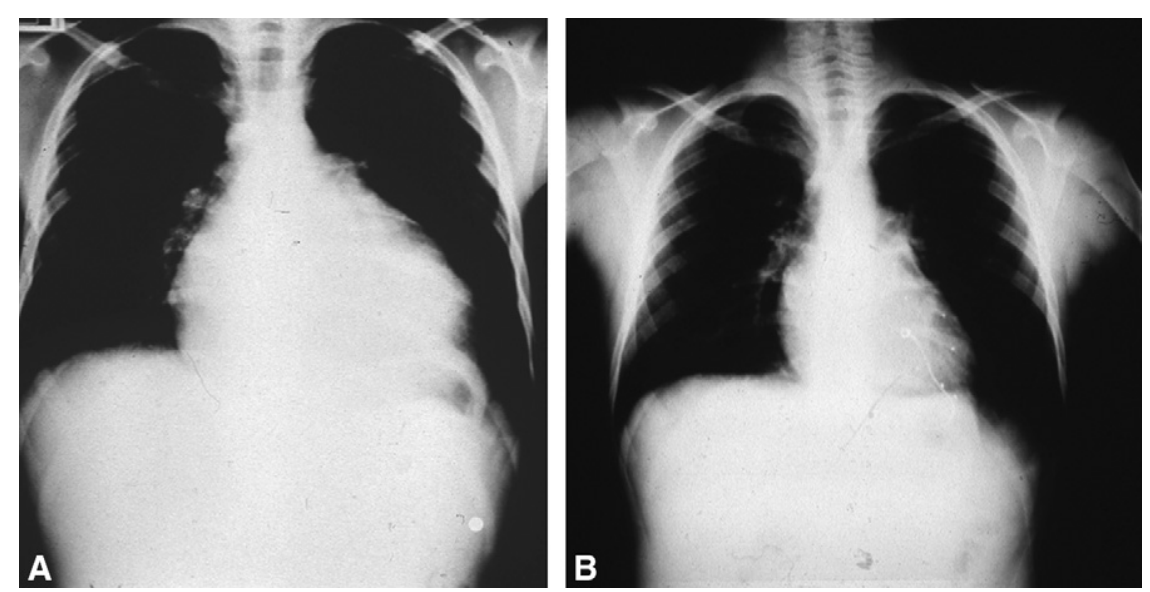

FIGURE 4. A, Chest $x$-ray film of a child who received an adult heart. B, Chest $x$-ray film of the same child 30 days after transplantation.

hemodynamic demands. We have only the numbers (dimensions and Z-scores) to prove it, but we would not be able to provide the underlying mechanisms. At present, we may only surmise that the shrinkage in transplanted adult hearts within a certain period of time followed by conforming to the somatic growth of the recipient is a physiologic adaptation to the pressure and volume demands of the growing body.

\section{STUDY LIMITATIONS}

Our study was not concerned with the effects of immunosuppression, hemodynamic performance, frequency and severity of acute and chronic rejections, myocardial fibrosis, or myocyte damage in correlation with the changes in cardiac dimensions and size disparity of transplanted hearts. A study of changes in peak systolic wall stress after transplant, which is BSA dependent, would be an important addition to the existing body of information. These issues are the subjects of on-going research in our institution.

\section{CONCLUSIONS}

This study demonstrates that despite size disparity, immunosuppression and denervation, the transplanted heart undergoes normal growth in diastolic dimensions, volumes, and myocardial mass over time appropriate for body growth after cardiac transplantation in infants and children. Ventricular remodeling occurs by a temporally reversible increase in ventricular diameter, volume, and mass within several weeks after transplantation, the extent of which is predicted by the physiologic requirements of the developing child, as demonstrated in the normalization and increase in dimensions and volumes over time.

We thank Anne M. Gale, Editor in the Life Sciences, for editorial assistance. We also appreciate the assistance of
Susanne Kosky, Julia Stein, Christine Detschades, Astrid Benhennour, and Mariano Francisco del Maria Javier.

\section{References}

1. Kantrowitz A, Haller JD, Joos H, Cerruti MM, Carstensen HE. Transplantation of the heart in an infant and an adult. Am J Cardiol. 1968;22782-90.

2. Conway J, Dipchand AI. Heart transplantation in children. Pediatr Clin North Am. 2010;57:353-73.

3. Kanter KR, Tam VKH, Vincent RN, Cuadrado AR, Raviele AA, Berg AM. Curren results with pediatric heart transplantation. Ann Thorac Surg. 1999;68:527-30.

4. Chen JM, Davies RR, Mital SR, Mercando ML, Addonisio LJ, Pinney SP, et al. Trends and outcomes in transplantation for complex congenital heart disease: 1984 to 2004. Ann Thorac Surg. 2004;78:1352-61.

5. Mayer JE Jr, Perry S, O'Brien P, Perez-Atayde A, Jonas RA, Castaneda AR, et al. Orthotopic heart transplantation for complex congenital heart disease. $J$ Thorac Cardiovasc Surg. 1990;99:484-92.

6. Backer CL, Zales VR, Idriss FS, Lynch P, Crawford S, Benson DW Jr, et al. Heart transplantation in neonates and children. J Heart Lung Transplant. 1992;11: 311-9.

7. Tischler MD, Lee RT, Plappert T, Mudge GH, St John Sutton M, Parker JD. Serial assessment of left ventricular function and mass after orthotopic heart transplantation: a 4 year longitudinal study. J Am Coll Cardiol. 1992;90:60-6.

8. Antunes ML, Spotnitz HM, Clark MB, Steinhardt MJ, Marboc CC, Smith CR, et al. Long-term function of human cardiac allografts assessed by twodimensional echocardiography. J Thorac Cardiovasc Surg. 1989;98:275-84.

9. Zales VR, Wright KL, Pahl E, Backer CL, Mavroudis C, Muster AJ, et al. Normal left ventricular muscle mass and mass/volume ratio after pediatric cardiac transplantation. Circulation. 1994;90(5 Pt 2):II61-5.

10. Bernstein D, Kolla S, Miner M, Pitlick P, Griffin M, Starnes V, et al. Cardiac growth after pediatric heart transplantation. Circulation. 1992;85:1433-9.

11. Zales VR, Wright KL, Muster AJ, Backer CL, Benson DW, Mavroudis C. Ventricular volume growth after cardiac transplantation in infants and children. Circulation. 1992;86(5 Suppl):II272-5.

12. Chinnock R, Baum M. Somatic growth in infant heart transplant recipients. Pediatr Transplant. 1998;2:30-4.

13. Hirsch R, Huddleston CB, Mendeloff EN, Sekarski TJ, Canter C. Infant and donor organ growth after heart transplantation in neonates with hypoplastic left heart syndrome. J Heart Lung Transplant. 1996;15:1093-100.

14. Tang L, Du W, Delius RE, L'Ecuyer JL, Zilberman MV. Low donor-to-recipien weight ratio does not negatively impact survival of pediatric transplant patients. PediatrTransplant. 2010;14:741-5.

15. Patel ND, Weiss ES, Nwakanma LU, Russell SD, Baumgartner WA, Shah AS, et al. Impact of donor-to-recipient weight ratio on survival after heart transplantation. Analysis of the United Work for Organ Sharing Database. Circulation. 2008;11:S83-8.

16. Fullerton DA, Gundry SR, Alonso de Begona J, Kawauchi M, Razzouk AJ, Bailey LL. The effects of donor-recipient size disparity in infant and pediatric heart transplantation. J Thorac Cardiovasc Surg. 1992;104:1314-9. 
17. Sethi GK, Lanauze P, Rosado LJ, Huston C, McCarthy MS, Butman S, et al. Clinical significance of weight difference between donor and recipient in heart transplantation. J Thorac Cardiovasc Surg. 1993;106:444-8.

18. Lehmkuhl H, Arizon J, Vigano M, Gerosa G, Maccherini M, Varnous S, et al. on behalf of the 2411 study investigators. Everolimus with reduced cyclosporine versus MMF with standard cyclosporine in de novo heart transplant recipients. Transplantation. 2009;88:115-22.

19. Schiller NB, Shah PM, Crawford M, DeMaria A, Devereaux R, Feigenbaum H, et al. Recommendations for quantitation of the left ventricle by two-dimensional echocardiography. J Am Soc Echocardiogr. 1989;2:358-67.

20. Silverman NH, Ports TA, Snider AR, Schiller NB, Carlsson E, Heilbron DC. Determination of left ventricular volume in children: echocardiographic and angiographic comparisons. Circulation. 1980;62:548-57.

21. Gutgesell HP, Rembold CM. Growth of the human heart relative to body surface area. Am J Cardiol. 1990;65:662-8.

22. Zak R. Factors controlling cardiac growth. In: Zak R, ed. Growth of the heart in health and disease. New York: Raven; 1984. p.165.

23. Shirali GS, Lombano F, Beeson L, Dyar DA, Mulla NF, Khan A, et al. Ventricular remodelling following infant-pediatric cardiac transplantation: does age at transplantation or size disparity matter? Transplantation. 1995;60:1467-72.

24. Rakusan K. Cardiac growth, maturation, and aging. In: Zak R, ed. Growth of the heart in health and disease. New York: Raven; 1984. p.131.

25. Chien KR, Knowlton KU, Zhu H, Chien S. Regulation of cardiac gene expression during myocardial growth and hypertrophy: molecular studies of an adaptive physiologic response. FASEB J. 1991;5:3037-46.

\section{Discussion}

Dr Charles B. Huddleston (St Louis, Mo). Thanks very much for providing me the manuscript and the slides and illustrations. It is an excellent presentation and analysis of the data.

We have looked at the same issue in only our infant population. We selected that infant population only because that would be a more consistent group and one in which the growth would be more obvious in terms of what the expectations would be. I think that you would not necessarily have to analyze the data specifically when you see a teenager come back for the 15-year follow-up after having had a transplant as an infant, for the heart must be growing. However, this study was a very nice objective demonstration of that.

Using ventricular dimensions is perhaps the most obvious way to assess the growth of a heart, but there are a number of variables that could play into the ventricular dimensions-resting heart rate, episodes of rejection, the presence of hypertension. I wonder whether using valvular dimensions, such as the mitral and aortic valve annular diameters, to assess the growth might actually be a more accurate way to figure this out. Do you have any comments about that?

Dr Delmo Walter. Thank you very much for your very constructive critique. That is certainly an excellent suggestion. We will look into all cases in which we have sufficiently complete echo data on mitral valve measurements of those children, which I am sure we have.

However, in this present study we did not concern ourselves with the mitral valve or the annular sizes to measure ventricular growth, although you have a point there. We were more interested in the growth of the myocardium inasmuch as this is the structure that is mostly affected in transplantation, especially in cases of rejection and immunosuppression. In addition, looking at the mitral valve annulus as an indicator of ventricular growth is a rational idea. If we look at these dimensions in the context of an unbalanced atrioventricular canal, this is valid and reliable. Perhaps we could apply this dimension in transplanted hearts. But I may be able to take a look at your suggestion.

Dr Huddleston. Have you actually ever encountered a single patient in whom you were suspicious that the growth had been inadequate, such as someone who is presenting late with restrictive type of physiology on their follow-up cardiac catheterizations?

Dr Delmo Walter. I cannot recall any particular case in which we have a restrictive physiology. I am not aware of such where we had to discuss a heart that did not grow sufficiently, or even underwent a retransplantation for that reason. In further studies, we will begin to look into those cases that lie at the borderline margins of the spectrum, like slow-growing or fast-growing hearts, and see whether there could be significant specific findings connected with those. I think this is a special point to consider in the study of growth of transplanted hearts. What I can recall, Dr Huddleston, is that we have 5 patients who were 3 standard deviations below normal at early follow-up but were close to normal range at late follow-up. This included 3 infants who have shown delayed linear growth while still receiving steroids and 2 children receiving highdose immunosuppressants because of rejection episodes. In these patients with poor linear growth, cardiac chamber growth occurred appropriate for BSA.

Dr Huddleston. Finally, there is this dogma, at least in the pediatric heart transplantation field, about taking small hearts, and to avoid that particularly in the presence of borderline pulmonary hypertension. I am not convinced that that is true, and I wondered whether you have any thoughts about taking small donors for some of your patients in light of the existing dogma.

Dr Delmo Walter. Thank you again for pointing out this dogma. The dogma lies on the inability of a smaller heart to overcome the pulmonary vascular resistance. It is known that the neonatal heart has impaired ability to increase stroke volume in response to an increased preload, and such an increase would be essential to provide adequate circulation for a larger recipient.

There are several reports to increase or extend the donor criteria so that the donor organ is available for anybody who needs it, like transplanting even small hearts whether the donor/recipient BSA ratio is more than 1.2 or discrepant. Patients who receive heart transplants from smaller donors rely on increased heart rate and elevated filling pressures to maintain appropriate cardiac output. Thus, the smaller donor heart has the ability to maintain circulation in a larger recipient using the maximum reserve over a substantial period of time and also has the capability to undergo hypertrophy despite immunosuppression. My senior author, Professor Hetzer, has reported on 30 patients who received hearts from smaller donors whose weight was up to $32 \%$ less than the recipient's weight. Of these, 13 patients had a weight difference between $5 \%$ and $10 \%, 10$ had a difference between $10 \%$ and $20 \%, 3$ had a difference between $21 \%$ and $30 \%$, and 4 had a difference of more than $30 \%$. It was concluded in this report that the postoperative graft function was acceptable for those recipients whose body weight did not exceed the donor's weight by more than $20 \%$. However, a weight difference of more than $20 \%$ was associated with significant postoperative graft dysfunction, although only 1 patient had a markedly elevated pulmonary vascular resistance. At the outset, the recipient should not have severe pulmonary hypertension or significantly elevated pulmonary vascular resistance, the graft should be healthy, and the ischemic time should be relatively short, at least less than 
4 hours. Of course, it is ideal to use the heart from a donor with an exact donor/recipient BSA ratio match. However, given the donor shortage, this is probably not achievable. Our data support the premise that in selected circumstances, smaller hearts do not adversely affect the early mortality or late outcome. We believe that it is safe to extend the widely accepted donor-recipient weight match criterion to less than $20 \%$. Nowadays, with clear-cut indication of transplantation, refinement in donor management, improvements in perioperative management, and improved immunosuppression, this dogma should therefore be nonexistent. I would like to say that this area of pediatric transplantation is a minefield when we talk about outcome of size mismatch on hemodynamics and growth. There are a lot of interesting areas of research we can really embark on to improve our understanding of pediatric heart transplantation.

Dr Ali Mumtaz (Norfolk, Va). Can you share with us any particular technical problems in trying to fit a very large heart into a very small chest? I noted in your protocol you said that you would accept a heart 4 times the size. I personally have had experience only up to a third. Even at that, at 3 times, in a 2-year-old child, I had to leave the chest open to wait for the swelling from previous congestive heart failure to go down and then close the chest. I am curious to see what measures you take to fit the heart 4 times the normal size.

Dr Delmo Walter. We apply the simple technique already known to all of us. We open both the pleura. When we cannot close the chest, we leave it open until the swelling decreases and then perform a delayed closure, although this is an instance we particularly avoid in transplantation. There were 2 or 3 cases in which we had to open the central fibrous body of the diaphragm and allow the heart to hang in the abdominal cavity for a time. Inasmuch as most of our patients were bridged to transplant with a mechanical circulatory assist device, their hearts were at the outset enlarged, and therefore their chest cavity as well, although their body weight or BSA was much less than their chest diameter. I would like to clarify a point I have mentioned in my presentation as well: When I said that it is our institutional policy to implant a donor heart 4 times larger than the recipient, I was not talking about the size of the heart; rather, I meant that the donor weight or BSA is maybe 4 times that of the recipient's weight or BSA.

Dr Emile A. Bacha (New York, NY). Can I clarify something? The heart is 4 times the size or the donor is 4 times the size? Also, are we talking BSA or weight? When you say 4 times the size, do you mean the donor heart you accept is up to 4 times the size, dimension, or do you accept 4 times BSA or 4 times weight?

Dr Delmo Walter. Four times the BSA, not 4 times the size of the recipient's heart itself, because that is not possible. The donor may be 4 times the BSA or weight of the recipient.

Dr Bacha. Right. That is why I am clarifying. Thank you very much. 